\title{
Breaks in the Chain of Comparative Advantage
}

\author{
E. Kwan Choi \\ Iowa State University \\ Henry Thompson \\ Auburn University
}

January 2009

The chain proposition of comparative advantage is the concept that when factor prices differ between two countries producing many products with two factors, every export of the capital abundant country would be more capital intensive than any of its imports. The present note shows that depending on factor endowments the full employment condition may break the chain. A labor abundant country cannot produce only products with labor intensities less than its capital labor endowment ratio and maintain full employment.

Choi, Dept of Economics, Iowa State University, Ames, IA 50011, 515-294-5999, fax 9913, kchoi@iastate.edu

Thompson, Economics, Comer Hall, Auburn University, Auburn, AL 36849, 334-844-2910, fax 5639,thomph1@auburn.edu 


\section{Breaks in the Chain of Comparative Advantage}

The chain proposition predicts the pattern of trade between two countries producing many products with two factors. In this $2 \times n$ world $(n>2)$ industry outputs cannot be uniquely determined from given factor endowments. In an attempt to resolve this indeterminacy Jones (1956, p. 6) writes:

"Ordering the commodities with respect to the capital-labor ratios employed in production is to rank them in order of comparative advantage. Demand conditions merely determine the dividing line between exports and imports; it is not possible to break the chain of comparative advantage by exporting, say, the third and fifth commodities and importing the fourth when they are ranked by factor intensity." Bhagwati (1972) convincingly demonstrates that the chain proposition may not hold when factor price equalization occurs. However, he also suggests (p. 1052) that the "proposition, although correct for the case where factor prices are not equalized, is untenable as literally stated. When factor-price equalization is realized, a not unimportant case, a variety of crisscrossings is possible."

Subsequently Deardorff (1979) investigates Bhagwati’s conjecture and argues that the chain proposition holds when factor prices are not equalized, a property cited widely, for instance by Bhagwati, Panagariya and Srinivasan (1998), Feenstra (2004), Romalis (2004), and Cavusoglu and Elmslie (2005). The chain proposition may be deemed to resolve production indeterminacy with many products but the present note shows the chain proposition is not necessary even if factor prices are not equalized.

A recent empirical study by Cavusoglu and Elmslie (2005) on nine US manufacturing industries for three periods (1970-1985, 1970-1990, 1970-2000) finds no empirical support for 
the chain proposition that all export industries are more capital intensive than import competing ones. ${ }^{1}$ Their empirical result suggests breaks in the chain of comparative advantage.

The present note shows that given full employment and depending on factor endowments, the capital abundant country may export a product more labor intensive than its imports. The present example assumes specialization with only exports produced. The point is that the capital abundant country cannot produce only products with capital intensities greater than its capital labor endowment ratio. For arbitrary endowments full employment may entail not producing a capital intensive product in favor of a more labor intensive one. If the endowment point lies outside the diversification cone of the most capital intensive goods, the chain of comparative advantage has to be broken to reach full employment.

\section{A Break in the Chain}

Consider the model with two factors and four products. Assume that country A is capital abundant $k^{A}>k^{B}$, where $k^{c}=K^{c} / L^{c}$ is the capital labor endowment ratio of country c. Assume factor prices are different and $w_{A} / r_{A}>w_{B} / r_{B}$. Factor price equalization FPE is not necessary with more products than factors. Also assume neoclassical production with no factor intensity reversals.

Figure 1 illustrates with unit value isoquants indicated by $1 / p_{j}^{c}$ for product $j$ and country $c$. If endowment points do not lie on expansion paths, each country must produce two products. Prices of these two products determine the country's factor prices with cost minimization along the two unit value isoquants as indicated in Figure 1.

The four products are ranked by capital intensity according to $k_{1}>k_{2}>k_{3}>k_{4}$. The wage rent ratio is higher in country $\mathrm{A}$ and the capital intensity for each product $j$ would be higher in country A, $k_{j}^{A}>k_{j}^{B}$. 
Deardorff (1979) assumes different factor prices for the two countries but does not consider production and employment. ${ }^{2}$ The implicit assumption is that the cone of diversification of the capital intensive products spans the endowment point of the capital abundant country, satisfied by the endowment point $E_{A}$ in Figure 1.

Consider, however, implications of the endowment point $E_{A}{ }^{*}$. With this endowment, the capital abundant country $A$ cannot produce only the two most capital intensive products 1 and 2 . If country $A$ produces product 1 it also must produce either product 3 or 4 with capital intensity less than $k^{A}$. In this example the intensity ranking chain of exports is broken when production is taken into account. Capital abundant country $A$ must produce at least one product with capital intensity less than its endowment ratio.

With endowment point $E_{A} *$ assume country $A$ produces product 3 as in Figure 1 . Note that the unit value isoquant for country $A$ lies below the one for country $B$ implying a higher price. While country $B$ could produce 3 more cheaply, country $A$ produces 3 perhaps selling at a loss to induce country $B$ to switch to product 2 . Also the lack of product 2 on the world market would imply a high price that would induce country $B$ to switch its production.

Country $A$ producing a product with no comparative advantage induces country $B$ to do the same, and full employment overrides intensity rankings in determining production. Equilibrium may be reached under other assumptions including models of unemployment friction. Note that the price of product 1 in Figure 1 does not change by assumption but the entire production equilibrium might be determined by introducing utility maximization.

Beyond the present example, the capital abundant country $A$ in Figure 1 at $E_{A} *$ can produce combinations $(1,3),(2,3),(1,4)$ or $(2,4)$ but not $(3,4)$. Labor abundant country $B$ would produce the other two products breaking the factor intensity chain. 


\section{Concluding Remarks}

The chain of comparative advantage with two factors and many products may have broken links with production and full employment in the model. The capital abundant country might have to produce some labor intensive products. The literature on the chain proposition implicitly assumes the capital abundant factor endowment point lies within the diversification cone of the most capital intensive goods, a condition that might not hold for arbitrary factor endowments and factor intensities.

Full employment and balanced trade are ingredients of a complete model with two factors and many goods. The present note suggests that as the number of products increases the international equilibrium would be more likely characterized by breaks in the chain of comparative advantage. 


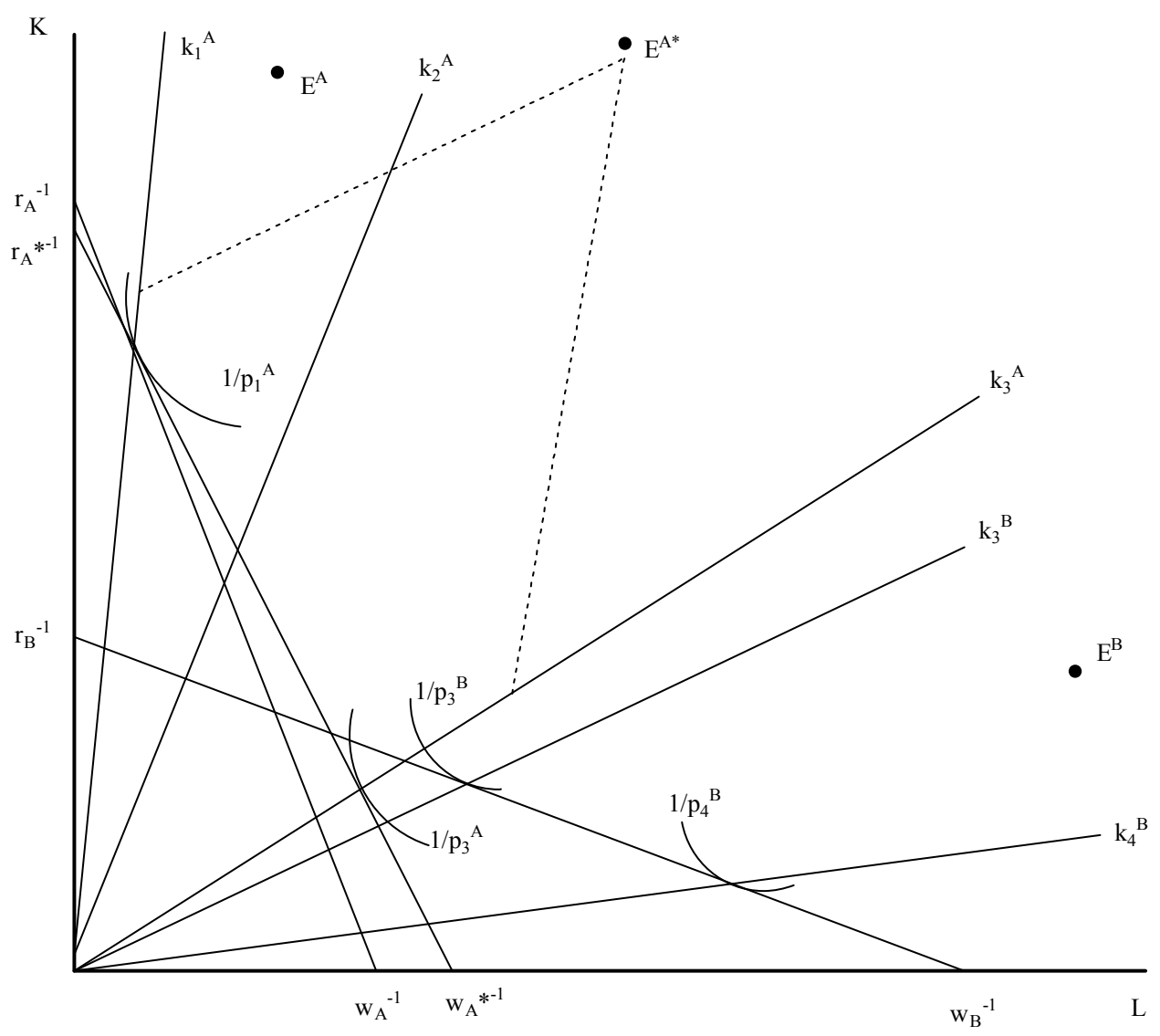

Figure 1. Production and a Broken Factor Intensity Chain 


\section{References}

Bhagwati, Jagdish (1972), "The Heckscher-Ohlin Theorem in the Multi-Commodity Case," Journal of Political Economy 80, 1052-55.

Bhagwati, Jagdish, Arvind Panagariya and T. N. Srinivasan (1998), Lectures in International Trade Second ed., MIT Press, 107-29.

Cavusoglu, Nevin and Bruce Elmslie (2005), "The Chain Version of Comparative Advantage: An Empirical Investigation," Review of World Economics 141, 404-21.

Deardorff, Alan (1979), "Weak Links in the Chain of Comparative Advantage," Journal of International Economics 9, 107-209.

Feenstra, Robert (2004), Advanced International Trade, Princeton University Press, 64-98.

Jones, Ronald (1956), "Factor Proportions and the Heckscher-Ohlin Theorem," Review of Economic Studies 24, 1-10.

Romalis, John (2004), "Factor Proportions and the Structure of Commodity Trade," American Economic Review 94, 67-97.

Vanek, Jarosalev (1968), "The Factor Proportions Theory: The n-factor Case,” Kyklos 21, 74956. 
${ }^{1}$ Cavusoglu and Elmslie (2005) noted a link between capital intensities and investment labor rankings, a result not predicted by the chain proposition.

${ }^{2}$ Deardorff assumes (i) two countries trade with no trade impediments so output prices are equal, (ii) production requires capital and labor are available in fixed supply in each country, (iii) production functions are identical between countries, concave, and linearly homogenous, (iv) products are ranked in terms of intensity with no factor intensity reversals, and (v) perfect competition in both countries. These assumptions imply FPE in the $2 \times 2$ case and can be extended to the even $n \times n$ case where $n>2$. These assumptions do not imply FPE with more products than factors. 